\title{
Engineered Osteochondral Grafts Using Biphasic Composite Solid Free-Form Fabricated Scaffolds
}

\author{
RACHEL M. SCHEK, Ph.D., 1,2,* JUAN M. TABOAS, Ph.D.,, 1,2, SHARON J. SEGVICH, M.S.,1 \\ SCOTT J. HOLLISTER, Ph.D., ${ }^{1,3,4}$ and PAUL H. KREBSBACH, D.D.S., Ph.D. ${ }^{1,2}$
}

\begin{abstract}
Tissue engineering has provided an alternative to traditional strategies to repair cartilage damaged by injury or degenerative disease. A successful strategy to engineer osteochondral tissue will mimic the natural contour of the articulating surface, achieve native mechanical properties and functional load-bearing ability, and lead to integration with host cartilage and underlying subchondral bone. Image-based design (IBD) and solid free-form (SFF) fabrication can be used to generate scaffolds that are load bearing and match articular geometry. The objective of this study was to utilize materials and biological factors in an integrated approach to regenerate a multitissue interface. Biphasic composite scaffolds manufactured by IBD and SFF fabrication were used to simultaneously generate bone and cartilage in discrete regions and provide for the development of a stable interface between cartilage and subchondral bone. Poly-L-lactic acid/hydroxyapatite composite scaffolds were differentially seeded with fibroblasts transduced with an adenovirus expressing bone morphogenetic protein 7 (BMP-7) in the ceramic phase and fully differentiated chondrocytes in the polymeric phase. After subcutaneous implantation into mice, the biphasic scaffolds promoted the simultaneous growth of bone, cartilage, and a mineralized interface tissue. Within the ceramic phase, the pockets of tissue generated included blood vessels, marrow stroma, and adipose tissue. This combination of IBD and SFF-fabricated biphasic scaffolds with gene and cell therapy is a promising approach to regenerate osteochondral defects.
\end{abstract}

\section{INTRODUCTION}

$\mathbf{T}$ The POOR REgEnERATIVE PROPERTIES of articular cartilage often necessitate surgical intervention after injury or degenerative disease. ${ }^{1-5}$ However, current therapies such as osteochondral grafting, chondroplasty, and prosthetic joint replacement have only partial or temporary success due to inadequate donor tissue availability, donor site morbidity, the risk of infection, abrasion of the cartilage surface, loosening of implants, and limited dura- bility of prosthetics. ${ }^{6-8}$ Tissue-engineering approaches have the potential to overcome the lack of donor tissue and to create a graft that contains biologically and mechanically functional tissue. A variety of tissue-engineering techniques have been developed to regenerate bone and cartilage. ${ }^{9-16}$ These studies have illustrated that engineered cartilage must integrate with the host tissue, provide a smooth and natural articulating surface, and bear functional mechanical loads. In attempts to satisfy these requirements, investigators have used a variety of

\footnotetext{
${ }^{1}$ Department of Biomedical Engineering, ${ }^{2}$ Department of Oral Medicine, Pathology, and Oncology, School of Dentistry, ${ }^{3}$ Department of Mechanical Engineering, and ${ }^{4}$ Department of Surgery, University of Michigan, Ann Arbor, Michigan.

*R.M.S. and J.M.T. contributed equally to this manuscript.
} 
techniques, including mechanically preconditioned engineered cartilage in vitro, to improve load-bearing properties $^{17,18}$ and contoured scaffolds to mimic articular surfaces. ${ }^{19,20}$ While varying degrees of success have been achieved by these approaches, no single technique has been able to satisfy the requirements of integration with host tissue, maintenance of a natural articulate contour, and mechanical function. To satisfy these requirements and also to generate a bone-cartilage interface along the entire length of a construct, a biphasic scaffold may be required.

Biphasic scaffolds are designed to guide the growth of two different tissues and satisfy different mechanical and biological requirements. Discrete regions of the scaffold are optimized for selective growth of the desired tissue by utilizing different material types, material properties, internal architectures (e.g., porosity, pore interconnectivity), and cells and biological factors. Such scaffolds have been investigated for ostochondral regeneration. In vitro culture of chondrocytes on scaffolds containing polymeric and ceramic phases showed maintenance of chondrocyte phenotype. ${ }^{21}$ Similar scaffolds seeded with chondrocytes, cultured in vitro, and then implanted in lapine osteochondral defects, led to the successful generation of both bone and cartilage and integration of the scaffold with the subchondral bone. ${ }^{22}$ Although these studies establish the potential of biphasic scaffolds for osteochondral regeneration, scaffolds seeded with both osteoprogenitor and chondroprogenitor cells may be necessary to achieve full integration with the host tissue and mechanical function. This may be particularly true in large defects or those deficient in skeletal progenitor cells. To address this limitation, investigators have seeded bone marrow stromal cells (BMSCs) differentiated into chondroblasts or osteoblasts onto hyaluron or ceramic structures, respectively, and cultured these structures in vitro. ${ }^{23}$ Assembly of these structures with fibrin glue created a biphasic tissue that, when subcutaneously implanted in mice, resulted in the formation of fibrocartilage on the hyaluron and bone on the ceramic regions. ${ }^{23}$ Taken together, these studies demonstrate the ability of biphasic scaffolds to support cell growth and differentiation into bone and cartilage. Further, these studies indicate that biphasic scaffolds show promise in promoting integration with host tissue and sustaining biological function.

Several limitations must be overcome to achieve successful treatment of human articular defects. Ideally, simultaneous growth will lead to the production of a mineralized tissue interface between cartilage and bone that will serve as a stiffness transition between both tissues akin to the tidemark in articular cartilage. Maintenance of a uniform tidemark may protect articular cartilage from damaged sustained during functional loading. Indeed, disruption of the subchondral bone architecture has been implicated in osteoarthritis. ${ }^{24,25}$ Rather than depending on the assembly of separate living structures that contain cultured cells, we propose to trigger simultaneous growth of bone and cartilage on one integrated biphasic scaffold to improve the mechanical properties of regenerated tissues.

Precise control over scaffold architecture may be used to enhance osteochondral regeneration. Control over the biphasic scaffold internal pore architecture may be used to create scaffolds with mechanical and biological properties that provide immediate mechanical function while promoting tissue ingrowth. ${ }^{26,27}$ Control over the exterior shape of the scaffold may be used to match the scaffold geometry with a defect site or the contours of the articular surface. Control over scaffold shape may be achieved using image data and micromilling. ${ }^{28}$ To create a scaffold with complex internal structures while providing for rapid and flexible manufacturing, computational design and solid free-form (SFF) fabrication techniques may be needed. SFF fabrication has previously been used to create biphasic scaffolds. Constructs composed of a porous poly-lactic-glycolic acid/poly-lactic acid (PLGA/PLA) upper phase and a porous PLGA/tricalcium phosphate lower phase provided for selective seeding of chondrocytes and the growth of cartilage in vitro. ${ }^{29}$ However, the efficacy of SFF scaffolds for biphasic tissue engineering remains unproven. In addition, the generation of a mineralized interface between regenerate cartilage and bone has not been demonstrated.

The objective of this study was to devise a tissue engineering strategy to regenerate osteochondral tissue in defects of varied size and shape. Image-based design (IBD) can be used to design scaffolds that match articulating surface geometry and minimize abrasion of regenerate cartilage. SFF fabrication can be used to build scaffolds that can bear functional loads, avoiding the need for preconditioning, while promoting regeneration. We hypothesized that an integrated composite scaffold may be used to simultaneously allow growth of both bone and cartilage progenitors in discrete regions of the scaffold. This would enhance integration of the scaffold in the implant site and provide for the development of a bone-cartilage interface that supplies appropriate mechanical support for the articular cartilage. Poly-L-lactic acid/hydroxyapatite (PLA/HA) discrete composite scaffolds were manufactured using IBD and SFF. Fibroblasts transduced with an adenovirus expressing bone morphogenetic protein 7 (BMP-7) were seeded in the ceramic phase and fully differentiated chondrocytes were seeded in the polymer phase. Composite scaffolds were subcutaneously implanted and grown for 4 weeks in a murine model. Our biphasic SFF scaffolds supported simultaneous growth of cartilage in the PLA phase, bone and blood vessels in the HA phase, and a mineralized cartilage interface tissue between the two phases. 


\section{MATERIALS AND METHODS}

\section{Scaffold design and manufacture}

The scaffold shape and internal pore architecture were defined using an image-based design (IBD) method previously described. ${ }^{30}$ IBD allows for the design of scaffolds with complex internal pore geometry and an external shape that matches patient-specific implant site requirements. Composite scaffolds were composed of two bonded cylinders, one hydroxyapatite (HA) and one poly-L-lactic acid (PLA, MW $_{\text {weightavg }}=147,000$; Birmingham Polymers, Birmingham, AL), each $5 \mathrm{~mm}$ in diameter and $3 \mathrm{~mm}$ in height. The HA phase contained 800or $300-\mu \mathrm{m}$-diameter orthogonal pores with a porosity of $50 \%$. These were manufactured by indirect solid freeform fabrication as previously described. ${ }^{31}$ Briefly, IBD data were converted to surface facet representation in *.STL format, using Imagedes (Voxelcon Computing, Ann Arbor, MI). The *.STL files were sliced with Modelworks software to create input files for three-dimensional ink jet wax printing on a Model Maker II (SolidScape, Merrimack, NH). An HA and acrylic slurry was cast into wax molds obtained from the three-dimensional printer and sintered. ${ }^{32}$ The polymer sponges were created by a salt-leaching technique as described previously. ${ }^{31}$ Sieved NaCl (Sigma, St. Louis, MO) particles 100-120 $\mu \mathrm{m}$ in size were packed into custom-made, 5-mm-diameter by 3-mm-high Teflon molds. Seventy microliters of $7.5 \%$ (w/v) PLA in methylene chloride (Sigma) was cast into the molds. The solvent was evaporated under vacuum overnight and the salt porogen was removed by soaking the mold in water for $48 \mathrm{~h}$.

\section{Assembly of composites}

The two phases of the scaffold were assembled before cell seeding and implantation. A thin polyglycolic acid (PGA) polymer film was placed between phases before assembly to serve as a barrier to cell infiltration during seeding and cell migration during growth (Fig. 1A). Twenty microliters of a saturated $60^{\circ}$ solution of PGA (molecular weight not reported by the manufacturer, viscosity in hexafluoroisopropanol reported as $1.71 \mathrm{dL} / \mathrm{g}$; Birmingham Polymers) in hexafluroisopropanol (Sigma) was dropped onto a glass slide and the ceramic scaffold was placed on top, thereby creating a film of PGA on one face of the HA. This film was allowed to dry and then peeled away from the cylinder circumference and ceramic face, leaving only that film which covered the opening of the pores (Fig. 1B). The two phases were then assembled by spreading $10 \mu \mathrm{L}$ of $7.5 \%$ PLA in methylene chloride on the exposed ceramic face and pressing the polymer sponge onto the ceramic base (Fig. 1C). Rods that traversed the ceramic and polymer phases were used to ensure a mechanically stable attachment between the phases, as previously described ${ }^{31}$ (Fig. 1D). PLA in methylene chloride $(25 \%, \mathrm{w} / \mathrm{v})$ was extruded in a straight line traversing both the ceramic and polymer phases. Completed scaffolds were allowed to dry overnight and sterilized by soaking in $70 \%$ ethanol for $24 \mathrm{~h}$.

\section{Scaffold imaging}

Final scaffolds were imaged by microcomputed tomography $(\mu \mathrm{CT})$ to visualize the internal structure, including continuity of the interface between the PLA and

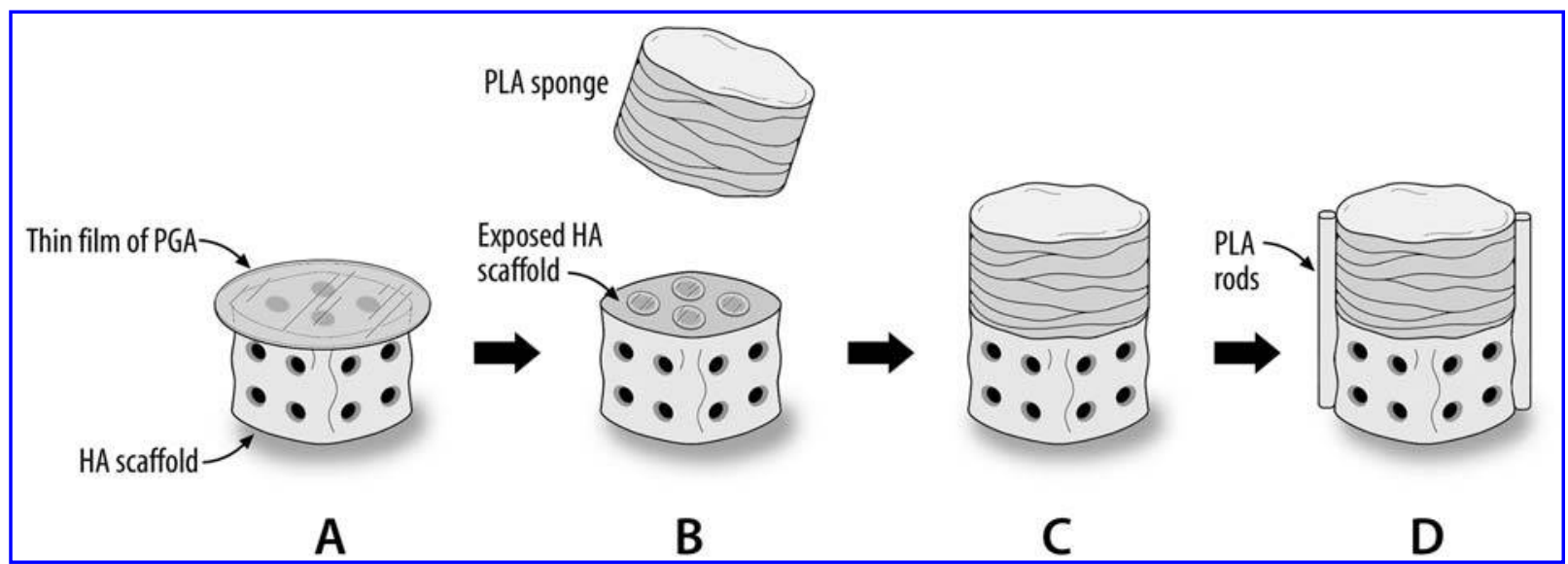

FIG. 1. PLA was used to join the polymer and ceramic phases of the composite scaffold. One face of the ceramic was coated with a thin film of PGA (A). The film was removed from the circumference and PLA was applied to the surface (B). The polymer sponge was pressed onto the ceramic scaffold, allowing the solubilized PLA to serve as adhesive (C). PLA struts were extruded on two opposite sides of the scaffold to further stabilize the composite (D). 
HA phases. Scans were performed through air to enhance contrast of the polymer phase on a model MS8-CMR100 scanner (EVS, London, ON, Canada) at $15-\mu \mathrm{m}$-voxel resolution and $80 \mathrm{kV}$. Noise was removed from the data sets and three-dimensional renderings were made, using custom routines written in IDL 5.5 (Research Systems, Boulder, $\mathrm{CO}$ ).

\section{Cell culture}

Articular cartilage was harvested from domestic pig knee joints obtained from a local slaughterhouse. Cartilage was scraped from articulating surfaces with a scalpel and diced into $1-\mathrm{mm}^{3}$ cubes. Chondrocytes were isolated with a $1.5-\mathrm{mg} / \mathrm{mL}$ solution of collagenase II (Sigma) in $\alpha$-minimum essential medium ( $\alpha$-MEM) containing penicillin-streptomycin, kanamycin, and amphotericin B (Fungizone; GIBCO, Frederick, MD). The tissue was digested overnight at $37^{\circ} \mathrm{C}$ under agitation and the resulting cell suspension was filtered through a double nylon sieve (70- $\mu \mathrm{m}$ pore size). The suspension was filtered and centrifuged at $700 \times g$ for $10 \mathrm{~min}$. The chondrocytes were resuspended in culture medium (CM, $\alpha$-MEM with $10 \% \mathrm{FBS}$ and $1 \%$ penicillin-streptomycin; GIBCO), and plated in tissue culture flasks (BD Biosciences, Lexington, KY). After $24 \mathrm{~h}$, adherent cells were used for cell seeding.

Primary human gingival fibroblasts (HGFs) were prepared from discarded tissue after oral surgery in compliance with the University of Michigan Institutional Review Board. Briefly, cells migrating from diced tissue onto tissue culture polystyrene were isolated and expanded in CM. ${ }^{33}$ Passage 4 fibroblasts were infected with AdCMV-BMP-7, a recombinant adenovirus construct expressing the murine BMP-7 gene under the control of the cytomegalovirus (CMV) promoter. The virus was created by Cre-lox recombination as previously described. ${ }^{34}$ Infections were performed overnight with 1000 plaqueforming units per cell. Such infected primary cells have been shown to form bone in vivo. ${ }^{35-38}$

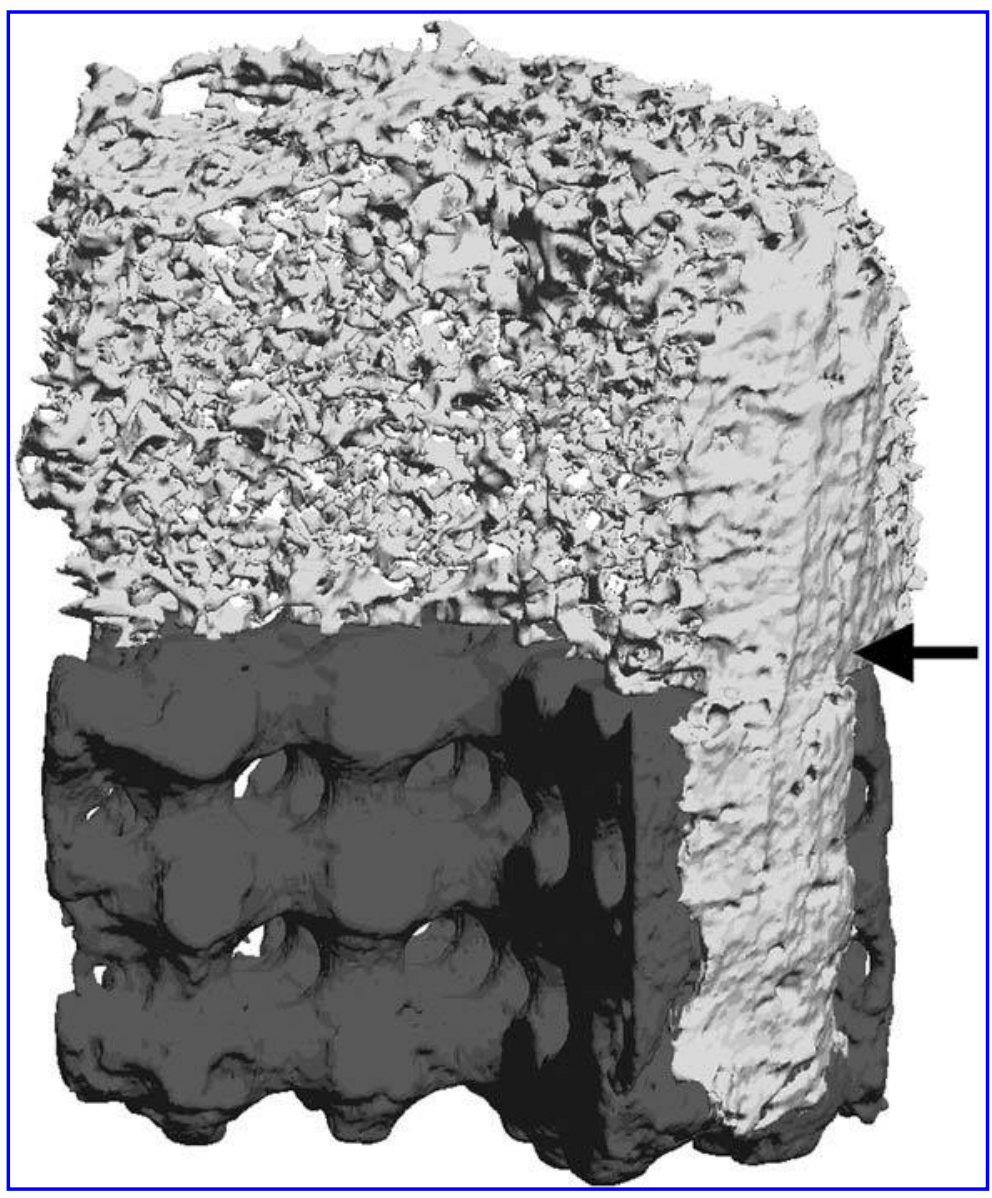

FIG. 2. A three-dimensional reconstruction of $\mu \mathrm{CT}$ data shows the polymer sponge phase (top), the HA phase (bottom, 300$\mu \mathrm{m}$ pore design), and the polymeric struts that transverse both phases (arrow). A pie slice portion of the scaffold has been removed from the image to reveal the pore architecture of the scaffold. 


\section{Cell seeding and scaffold implantation}

A two-step process was used to seed cells into the polymer and ceramic phases of the scaffold. Transduced HGFs were suspended in bovine plasma-derived fibrinogen (50 mg/mL in $\alpha$-MEM; Sigma). Cells ( $10^{6}$ in $20 \mu \mathrm{L}$ ) were pipetted into the ceramic phase of the composite scaffold and the scaffold was immediately placed onto a $20-\mu \mathrm{L}$ drop of bovine plasma-derived thrombin (100 U/mL; Sigma). Fibrinogen gelation occurred quickly on contact with the thrombin. To ensure complete gelation throughout the scaffold volume, the scaffold was left undisturbed in thrombin for $40 \mathrm{~min}$. Chondrocytes were suspended in $\mathrm{CM}$ and $10^{6}$ cells in $20 \mu \mathrm{L}$ were pipetted into the polymer sponge phase and allowed to adhere for $1 \mathrm{~h}$ in a $37^{\circ} \mathrm{C}$ incubator. The scaffolds were then immediately implanted.

Twelve composite scaffolds were implanted subcutaneously into 5- to 8-week-old immunocompromised mice (N:NIH-bg-nu-xid; Charles River, Wilmington, MA). Animals were anesthesized with intramesenteric injections of ketamine-xylazine (50 and $5 \mu \mathrm{g} / \mathrm{g}$, respectively) in saline. Dorsal subcutaneous pockets were created by blunt dissection and four composite scaffolds were inserted into each mouse. Surgical sites were closed with wound clips.

\section{Evaluation of implants}

Mice were killed after 4 weeks. The harvested implants were fixed with Z-Fix (Anatech, Battle Creek, MI) and stored in $70 \%$ ethanol for microcomputed tomography $(\mu \mathrm{CT})$ analysis and paraffin processing. Specimens were $\mu \mathrm{CT}$ scanned in distilled water at $10-\mu \mathrm{m}$-voxel resolu- tion. Three-dimensional isosurface renderings were made with MicroView v 1.1.1 (GE Medical Systems, London, ON, Canada) to visualize bone and ceramic.

Specimens were then demineralized with RDO (APEX Engineering Products, Plainfield, IL). ${ }^{31}$ The demineralization process also removed the HA phase of the scaffold. The specimens were then embedded in paraffin, sectioned at $7 \mu \mathrm{m}$, and stained with either hematoxylin and eosin $(\mathrm{H} \& \mathrm{E})$ or with safranin $\mathrm{O}$ and fast green. The safranin $\mathrm{O}$ stained glycosaminoglycans (GAGs) red and the fast green stained collagenous tissues brown.

\section{RESULTS}

The final manufactured composite scaffolds matched the image based design. The PLA polymer sponge consisted of 50- to 100- $\mu \mathrm{m}$-wide interconnected pores as evidenced by $\mu \mathrm{CT}$. A slight separation between the PLA sponge and HA ceramic phases was visible in the $\mu \mathrm{CT}$ (Fig. 2). The PLA rods connecting the phases were in intimate contact with both the PLA and HA phases. The integrity of the composite scaffold was sufficient to withstand surgical manipulation and subsequent implantation.

To determine the potential for the growth and differentiation of bone and cartilage on the scaffolds, cells were loaded into the biphasic scaffold and implanted. Four weeks after implantation, the constructs were removed and analyzed. The implants were encapsulated in soft connective tissue and no necrotic tissue or inflammation was observed in any of the animals. Demineralization of the implants allowed paraffin sectioning of the scaffold by removing the ceramic portion of the scaffold; in his-
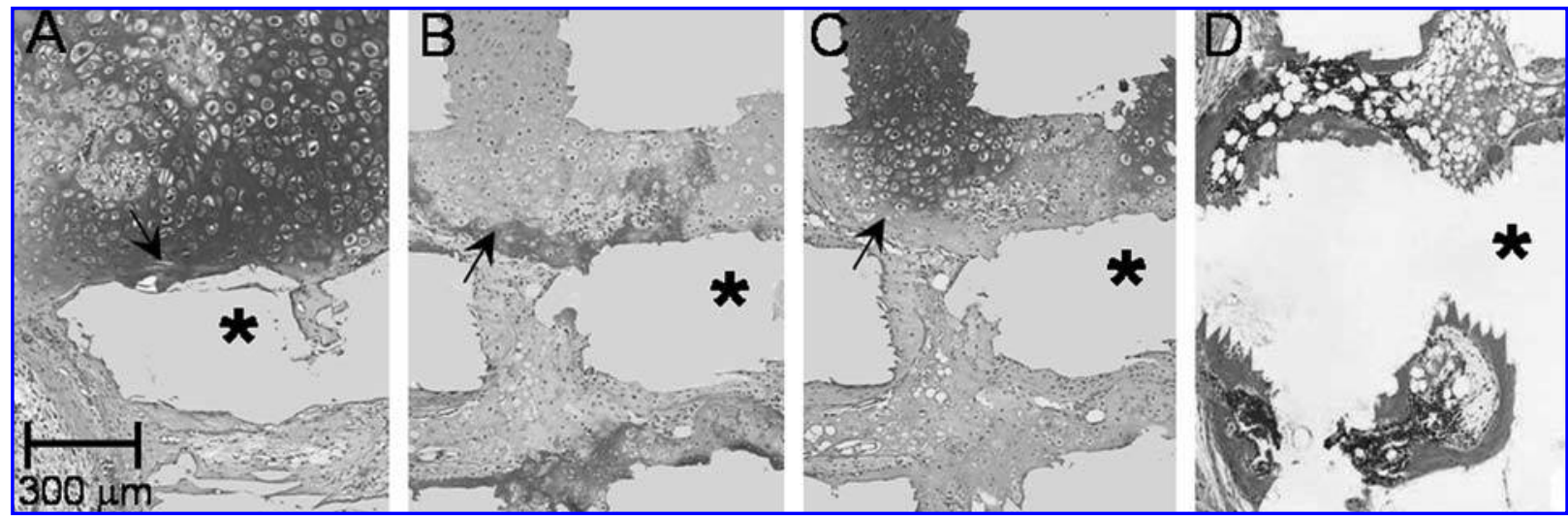

FIG. 3. Scaffolds were demineralized before sectioning, resulting in empty areas (marked with asterisks) that were previously occupied by HA. Safranin O and fast green staining showed a large area of pink-stained cartilage (arrow) in the polymer sponge, in contact with the green-brown-stained bone formed in the ceramic phase (A). Small pockets of cartilage were also observed within the pores of the ceramic phase of the scaffold (C, arrow). Comparison with H\&E sections showed that this tissue was adjacent to areas of tissue that stained positive for eosin, but contained rounded chodrocyte-like cells (B, arrows). H \& E staining showed the formation of bone and marrow throughout the ceramic scaffold (D). All sections are from an HA scaffold with 300$\mu \mathrm{m}$ pores. 
tological sections, areas that were formerly occupied by HA appear empty (white). Safranin O staining revealed the presence of GAGs in the PLA sponge of the scaffold, indicating chondrocyte synthesis of cartilage matrix (Fig. $3 \mathrm{~A})$. The centers of the sponge displayed low safranin $\mathrm{O}$ staining whereas the outer regions and interface with the HA ceramic displayed strong staining. Apical regions of the polymer sponge consistently stained with safranin $\mathrm{O}$. Cartilage was found in intimate contact with the ceramic and infiltrating the ceramic pores at the polymer-ceramic interface. Small pockets of cartilage were also observed deep within the pores of the ceramic phase (Fig. 3C). Comparison of adjacent sections stained with hematoxylin and eosin suggests that some regions of cartilage tissue within pores underwent mineralization as evidenced by the strong eosin stain and hypertrophic chondrocyte morphology (Fig. 3B). This mineralized cartilage was also present at the interface between the polymer and ceramic phases of the composite. These results were confirmed by the three-dimensional reconstructions of the $\mu \mathrm{CT}$ data. CT scans demonstrated mineralized tissue at the interface between the polymer sponge and porous ceramic, in intimate contact with the HA phase (Fig. 4). Significant bone growth was observed in the pores of the HA phase and on the HA outer surface, often filling the pore openings with bone. In addition, smaller mineralized regions were observed in the PLA phase near the cylinder walls of the sponge.

Several other tissue types were found in the composite scaffolds. Blood vessels were observed in the ceramic but not the polymer phases of the composite. Vessels were oriented longitudinally along the length of ceramic pores, within fibrous and bone tissue and traversed into the central region of the ceramic phase (Fig. 5). Fibrous tissue was observed within both the ceramic and polymeric phases of the tissue. Within the HA scaffold pores, a variety of tissue types were observed, including bone, fatty tissue, blood vessels, and marrow stroma (Fig. 3D).

\section{DISCUSSION}

The objective of this study was to utilize materials and biological factors in an integrated approach to regenerate a multitissue interface. Our results demonstrate that IBD and SFF-manufactured biphasic polymer-ceramic scaffolds support the concurrent formation of bone and cartilage in discrete phases of the assembled scaffold to generate an integrated tissue-engineered osteochondral construct. Concurrent tissue growth provided for the development of a mineralized tissue interface between cartilage in the PLA sponge phase and bone in the HA ceramic phase (Figs. 3 and 4). This interface tissue should provide a transition in stiffness between the regenerated cartilage and bone. However, some regions of the inter-

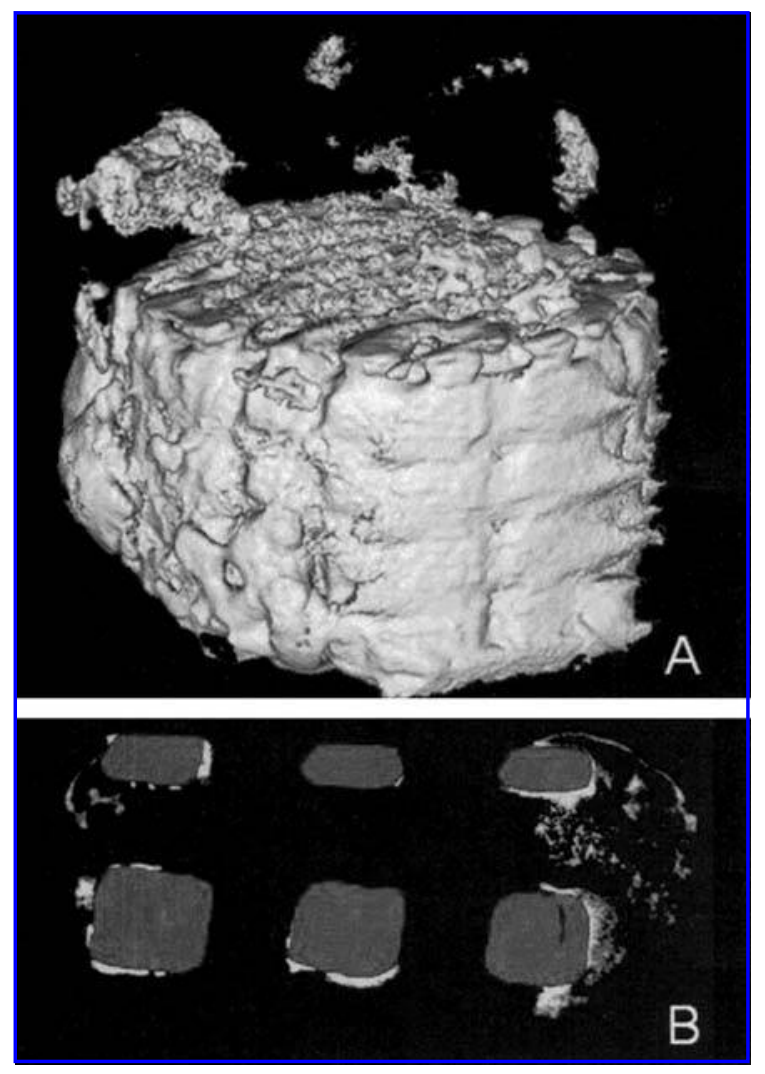

FIG. 4. Three-dimensional reconstructions of $\mu \mathrm{CT}$ data of the ceramic phase of the scaffolds demonstrated that bone was extensive and occluded the ceramic pores (diameter, $300 \mu \mathrm{m}$ ). Small amounts of mineralized tissue were also present in the polymer phase of scaffold. The polymer sponge, while intact, did not appear in the $\mu \mathrm{CT}$ image, because of the scanning protocol used (A). A cross-sectional view of an HA phase (shown in gray; pore diameter, $800 \mu \mathrm{m}$ ) shows scattered bone (white) growth within and around the scaffold $(\mathbf{B})$.

face were devoid of this mineralized tissue and instead displayed cartilage in intimate contact with the ceramic. The SFF-designed channels within the ceramic phase guided vascularization, a process that is critical to produce a biologically functional tissue. These scaffolds also supported the growth of fat and stroma, demonstrating their potential to fully mimic native skeletal tissue. Taken together, SFF-manufactured biphasic scaffolds differentially seeded with osteo- and chondroprogenitors can generate osteochondral tissue resembling native tissue, including vascular subchondral bone and an interface tissue between bone and articular cartilage that is similar to the tidemark seen in articulating surfaces. The design and composition of the scaffolds may be modified to satisfy the mechanical requirements in a skeletal site. ${ }^{27}$

The combined use of gene therapy and SFF biphasic scaffolds represents a new strategy for the repair of human osteochondral defects and for joint replacement. Because human defects will be comparatively large, seed- 


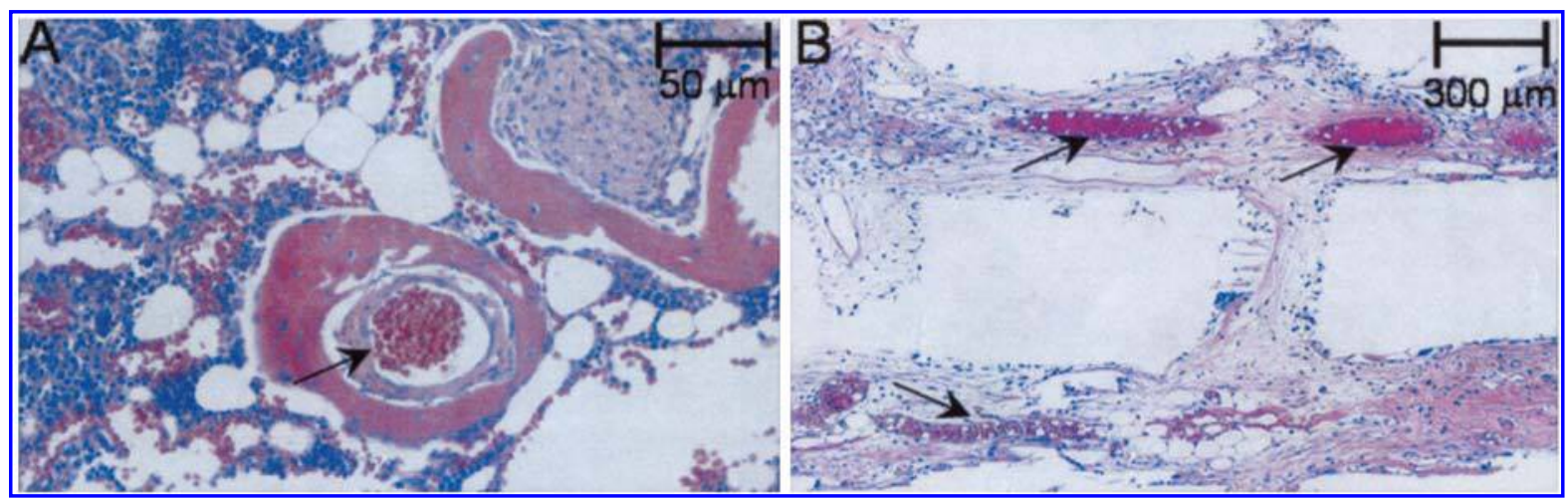

FIG. 5. H \& E staining of blood vessels that grew in the HA phase of the scaffolds; arrows show a vessel within bone (perpendicular to pore cross-section) (A), and another growing through fibrous tissue along the length of the pore, demonstrating that vessel growth was directed by the pore structure of the HA (B).

ing of implants with cells may be necessary to provide a cell pool for tissue regeneration. A similar lack of regenerative cells may be problematic in human defects in which disease or therapeutic irradiation have depleted progenitor cell polulations. ${ }^{39-42}$ In this study, we have demonstrated that implantation of our cell-containing scaffolds led to growth of skeletal tissues in a nonorthotopic (subcutaneous) site, in which a similar lack of progenitor cells exists. Bone formation was induced by the presence of nonosseous progenitor cells transduced with a BMP-7 adenoviral construct. This gene therapy approach provides for bone formation from cell populations that are easily harvested and expanded compared with osteoblasts or bone marrow stromal cells. ${ }^{37,38}$

The SFF biphasic scaffolds are advantageous for several reasons. They can be designed to fit patient-specific injuries and match articular surface geometry, using defect imaging and IBD. ${ }^{30}$ The biphasic components can be used to differentially regulate cell differentiation and growth, promoting the regeneration of bone and vasculature in the ceramic component while maintaining the growth of cartilage in the polymeric component. Each phase may be differentially seeded or loaded with growth and gene therapy factors. In addition, biphasic SFF scaffolds may be designed to carry functional loads. ${ }^{43}$ The IBD and SFF methods described here can be applied to create larger scaffolds for human skeletal defects. Such scaffolds will likely be exposed to larger mechanical forces than those present in this model, particularly if they are used in load-bearing orthotopic sites.

To create a strong mechanical interface between the ceramic and polymer phases of a larger composite scaffold, a number of polymeric struts, similar to the rods created on the sides of the small implants used in this study, may be required. We have previously demon- strated manufacture of such scaffolds with polymeric struts. ${ }^{31}$ Although the effect of polymeric struts on bone and cartilage regeneration is a current subject of study, such struts are similar in size and composition to the PLA pins and screws increasingly used in clinical practice for cartilage and bone anchoring. ${ }^{44-46}$ IBD coupled with SFF fabrication provides great flexibility in the design and manufacture of scaffolds to meet a variety of often conflicting clinical requirements, such as minimizing the number of struts while maintaining sufficient mechanical properties.

Although the biphasic scaffolds were designed to control cell seeding, greater control over the spatial distribution of regenerate tissue is desired. The polymer phase displayed low safranin $\mathrm{O}$ staining in the sponge centers, indicating the absence of cartilage. Chondrocyte infiltration into the polymer sponge may have been hindered by the 50- to $100-\mu \mathrm{m}$ pore size. Larger pores with enhanced interconnectivity are likely required to achieve uniform seeding. In addition, small amounts of mineralized tissue were observed in some constructs within the polymer phase that may have been the result of transduced HGF migration or diffusion of BMP-7. BMP-7 produced by the fibroblast in the ceramic phase may also have initiated osteogenesis by the chondrocytes in the polymeric phase.

The mineralized tissue interface between bone and cartilage consisted of mineralized cartilage and was often present at the junction of the polymer and ceramic phases of the composite, as evidenced by the safranin $\mathrm{O}$ and eosin stain and hypertrophic chondrocyte cell morphology (Fig. 3). However, cartilage was also found in direct apposition with the ceramic at the polymer-ceramic interface. The PGA barrier over the ceramic pores may have prevented osteoblasts from interacting with chondrocytes in these regions and from producing a bone-car- 
tilage interface. In addition, pockets of tissue within the ceramic phase stained positive for glycosaminoglycans (GAGs), indicating the presence of cartilage. These pockets were often located next to mineralized cartilage (Fig. $3)$. The origin of this cartilage is unclear. It is possible that the PGA barrier over the ceramic pores failed to prevent some chondrocytes from infiltrating the ceramic phase during seeding. However, it is also possible that the BMP-7-transduced HGFs may have induced cartilage formation. BMP-7 is known to induce bone formation via endochondral ossification. ${ }^{47-50}$ Considering that virally transduced HGFs secrete BMP-7 that may act on host cells, it is also possible that the cartilage tissue is of host origin. Host cells exposed to the BMP-7 may have undergone delayed endochondral ossification relative to that of the implanted HGFs and yielded a chimeric tissue. ${ }^{38}$ Modifications to the cell-seeding method may be used to minimize the presence of undesired cell types in either phase of the scaffold. In addition, lower numbers of transduced cells may be used to decrease the local concentration of BMP-7. Finally, advanced understanding of how the scaffold internal architecture regulates interface tissue formation may be used to enhance formation of a uniform mineralized tissue interface between bone and cartilage similar to the tide mark.

In conclusion, image-based design (IBD) and solid free-form (SFF)-manufactured hydroxyapatite (HA) and poly(L-lactide) PLA biphasic composite scaffolds, coupled with differential cell seeding and gene therapy, generated osteochondral tissue, including cartilage, vascularized bone, and an organized bone-cartilage interface. In an ectopic site, the tissue formation was not highly uniform, but these results suggest that these methods will be effective in regenerating osteochondral tissue in situ. We hope to test the performance of a similar construct in an orthotopic site and further investigate mechanical performance, implant degradation, and tissue formation. IBD and SFF fabrication can be used to manufacture biphasic composites that are capable of carrying functional loads on implantation, replicating articular surface geometry, and promoting integration with host tissues. The use of an integrated composite manufactured via SFF fabrication coupled with the use of osteo- and chondroprogenitor cells in situ is a promising strategy for the regeneration of functional articular surfaces.

\section{ACKNOWLEDGMENTS}

The authors thank R.B. Rutherford for supplying HGFs and acknowledge funding from National Institutes of Health grants HD07505 (J.M.T.), DE13608 (S.J.H.), AR48414 and DE13835 (P.H.K.), and AR46024 (Uni- versity of Michigan Bone Center). R.M.S. was supported by an NIH training grant in tissue engineering and regeneration (DE07057-26).

\section{REFERENCES}

1. Hjertquist, S., and Lemperg, R. Histological, autoradiographic and micromechanical studies of spontaneously healing osteochondral articulat defects in adult rabbits. Calcif. Tissue Res. 8, 54, 1971.

2. Mankin, H.J. The response of articular cartilage to mechanical injury. J. Bone Joint Surg. Am. 64, 460, 1982.

3. Buckwalter, J.A. Articular cartilage injuries. Clin. Orthop. 402, 21, 2002.

4. Hunziker, E.B. Articular cartilage repair: Basic science and clinical progress - a review of the current status and prospects. Osteoarthritis Cartilage 10, 432, 2002.

5. Jakob, R.P., Mainil-Varlet, P., and Gautier, E. Isolated articular cartilage lesion: Repair or regeneration. Osteoarthritis Cartilage 9(Suppl. A), S3, 2001.

6. Poitout, D., and Novakovitch, G. Use of allografts in oncology and traumatology. Int. Orthop. 11, 169, 1987.

7. Schmalzried, T.P., and Callaghan, J.J. Wear in total hip and knee replacements. J. Bone Joint Surg. Am. 81, 115, 1999.

8. Mandelbaum, B.R., Browne, J.E., Fu, F., Micheli, L., Mosely, J.B., Jr., Erggelet, C., Minas, T., and Peterson, L. Articular cartilage lesions of the knee. Am. J. Sports Med. 26, 853, 1998.

9. Vunjak-Novakovic, G., Martin, I., Obradovic, B., Treppo, S., Grodzinsky, A.J., Langer, R., and Freed, L.E. Bioreactor cultivation conditions modulate the composition and mechanical properties of tissue-engineered cartilage. J. Orthop. Res. 17, 130, 1999.

10. Dounchis, J.S., Bae, W.C., Chen, A.C., Sah, R.L., Coutts, R.D., and Amiel, D. Cartilage repair with autogenic perichondrium cell and polylactic acid grafts. Clin. Orthop. 377, 248, 2000.

11. Alsberg, E., Anderson, K., Albeiruti, A., Rowley, J., and Mooney, D. Engineering growing tissues. Proc. Natl. Acad. Sci. U.S.A. 99, 12025, 2002.

12. Martinek, V., Ueblacker, P., and Imhoff, A.B. Current concepts of gene therapy and cartilage repair. J. Bone Joint Surg. Br. 85, 782, 2003.

13. Holland, T.A., and Mikos, A.G. Advances in drug delivery for articular cartilage. J. Control. Release 86, 1, 2003.

14. Brittberg, M., Tallheden, T., Sjogren-Jansson, B., Lindahl, A., and Peterson, L. Autologous chondrocytes used for articular cartilage repair: an update. Clin. Orthop. 391(Suppl.), S337, 2001.

15. Solchaga, L.A., Goldberg, V.M., and Caplan, A.I. Cartilage regeneration using principles of tissue engineering. Clin. Orthop. 391(Suppl.), S161, 2001.

16. Palmer, G., Pascher, A., Gouze, E., Gouze, J.N., Betz, O., Spector, M., Robbins, P.D., Evans, C.H., and Ghivizzani, S.C. Development of gene-based therapies for cartilage repair. Crit. Rev. Eukaryot. Gene Expr. 12, 259, 2002.

17. Pei, M., Solchaga, L.A., Seidel, J., Zeng, L., Vunjak-No- 
vakovic, G., Caplan, A.I., and Freed, L.E. Bioreactors mediate the effectiveness of tissue engineering scaffolds. FASEB J. 16, 1691, 2002.

18. Waldman, S.D., Spiteri, C.G., Grynpas, M.D., Pilliar, R.M., Hong, J., and Kandel, R.A. Effect of biomechanical conditioning on cartilaginous tissue formation in vitro. J. Bone Joint Surg. Am. 85A(Suppl. 2), 101, 2003.

19. Isogai, N., Landis, W., Kim, T.H., Gerstenfeld, L.C., Upton, J., and Vacanti, J.P. Formation of phalanges and small joints by tissue-engineering. J. Bone Joint Surg. Am. 81, 306, 1999.

20. Weng, Y., Cao, Y., Silva, C.A., Vacanti, M.P., and Vacanti, C.A. Tissue-engineered composites of bone and cartilage for mandible condylar reconstruction. J. Oral Maxillofac. Surg. 59, 185, 2001.

21. Kreklau, B., Sittinger, M., Mensing, M.B., Voigt, C., Berger, G., Burmester, G.R., Rahmanzadeh, R., and Gross, U. Tissue engineering of biphasic joint cartilage transplants. Biomaterials 20, 1743, 1999.

22. Schaefer, D., Martin, I., Jundt, G., Seidel, J., Heberer, M., Grodzinsky, A., Bergin, I., Vunjak-Novakovic, G., and Freed, L.E. Tissue-engineered composites for the repair of large osteochondral defects. Arthritis Rheum. 46, 2524, 2002.

23. Gao, J., Dennis, J., Solchaga, L., Awadallah, A., Goldberg, V., and Caplan, A. Tissue-engineered fabrication of an osteochondral composite graft using rat bone marrow-derived mesenchymal stem cells. Tissue Eng. 7, 363, 2001.

24. Radin, E.R., Paul, I.L., and Rose, R.M. Pathogenesis of primary osteoarthritis. Lancet 1, 1395, 1972.

25. Burr, D.B., and Schaffler, M.B. The involvement of subchondral mineralized tissues in osteoarthrosis: Quantitative microscopic evidence. Microsc. Res. Tech. 37, 343, 1997.

26. Hutmacher, D. Scaffolds in tissue engineering bone and cartilage. Biomaterials 21, 2529, 2000.

27. Hollister, S., Maddox, R., and Taboas, J. Optimal design and fabrication of scaffolds to mimic tissue properties and satisfy biological constraints. Biomaterials 23, 4095, 2002.

28. Hung, C.T., Lima, E.G., Mauck, R., Lu, H.H., and Ateshian, G.A. Considerations for the design of biphasic anatomically shaped constructs for articular cartilage tissue engineering. Presented at the Orthopaedic Research Society 49th Annual Meeting, New Orleans, LA, 2003. Abstract 971 .

29. Sherwood, J.K., Riley, S.L., Palazzolo, R., Brown, S.C., Monkhouse, D.C., Coates, M., Griffith, L.G., Landeen, L.K., and Ratcliffe, A. A three-dimensional osteochondral composite scaffold for articular cartilage repair. Biomaterials 23, 4739, 2002.

30. Hollister, S.J., Levy, R.A., Chu, T.M., Halloran, J.W., and Feinberg, S.E. An image-based approach for designing and manufacturing craniofacial scaffolds. Int. J. Oral Maxillofac. Surg. 29, 67, 2000.

31. Taboas, J.M., Maddox, R.D., Krebsbach, P.H., and Hollister, S.J. Indirect solid free form fabrication of local and global porous, biomimetic and composite $3 \mathrm{D}$ polymer-ceramic scaffolds. Biomaterials 24, 181, 2003.

32. Chu, T.M., Hollister, S.J., Halloran, J.W., Feinberg, S.E., and Orton, D.G. Manufacturing and characterization of 3
D hydroxyapatite bone tissue engineering scaffolds. Ann. N.Y. Acad. Sci. 961, 114, 2002.

33. Rutherford, R.B., TrailSmith, M.D., Ryan, M.E., and Charette, M.F. Synergistic effects of dexamethasone on platelet-derived growth factor mitogenesis in vitro. Arch. Oral Biol. 37, 139, 1992.

34. Franceschi, R.T., Wang, D., Krebsbach, P.H., and Rutherford, R.B. Gene therapy for bone formation: In vitro and in vivo osteogenic activity of an adenovirus expressing BMP7. J. Cell Biochem. 78, 476, 2000.

35. Gazit, D., Turgeman, G., Kelley, P., Wang, E., Jalenak, M., Zilberman, Y., and Moutsatsos, I. Engineered pluripotent mesenchymal cells integrate and differentiate in regenerating bone: A novel cell-mediated gene therapy. J. Gene Med. 1, 121, 1999.

36. Lieberman, J.R., Le, L.Q., Wu, L., Finerman, G.A., Berk, A., Witte, O.N., and Stevenson, S. Regional gene therapy with a BMP-2-producing murine stromal cell line induces heterotopic and orthotopic bone formation in rodents. J. Orthop. Res. 16, 330, 1998.

37. Rutherford, R.B., Moalli, M., Franceschi, R.T., Wang, D., $\mathrm{Gu}, \mathrm{K}$., and Krebsbach, P.H. Bone morphogenetic proteintransduced human fibroblasts convert to osteoblasts and form bone in vivo. Tissue Eng. 8, 441, 2002.

38. Krebsbach, P.H., Gu, K., Franceschi, R.T., and Rutherford, R. B. Gene therapy-directed osteogenesis: BMP-7-transduced human fibroblasts form bone in vivo. Hum. Gene Ther. 11, 1201, 2000.

39. Hernigou, P., Beaujean, F., and Lambotte, J.C. Decrease in the mesenchymal stem-cell pool in the proximal femur in corticosteroid-induced osteonecrosis. J. Bone Joint Surg. Br. 81, 349, 1999.

40. Murphy, J.M., Dixon, K., Beck, S., Fabian, D., Feldman, A., and Barry, F. Reduced chondrogenic and adipogenic activity of mesenchymal stem cells from patients with advanced osteoarthritis. Arthritis Rheum. 46, 704, 2002.

41. Wall, E., and Von Stein, D. Juvenile osteochondritis dissecans. Orthop. Clin. North Am. 34, 341, 2003.

42. Nussenbaum, B., Rutherford, R.B., Teknos, T.N., Dornfeld, K.J., and Krebsbach, P.H. Ex vivo gene therapy for skeletal regeneration in cranial defects compromised by preoperative radiation. Hum. Gene Ther. 14, 1107, 2003.

43. Saito, E., Flanagan, C.L., Taboas, J.M., Kohn, D.H., Krebsbach, P.H., and Hollister, S.J. Mechanical and structural properties of designed PLLA, PLGA, and PGA scaffolds made by indirect solid free form fabrication. Presented at the Society for Biomaterials 29th Annual Meeting, 2003. Abstract 35.

44. Suuronen, R., Kallela, I., and Lindqvist, C. Bioabsorbable plates and screws: Current state of the art in facial fracture repair. J. Craniomaxillofac. Trauma 6, 19, 2000.

45. Peltoniemi, H., Ashammakhi, N., Kontio, R., Waris, T., Salo, A., Lindqvist, C., Gratz, K., and Suuronen, R. The use of bioabsorbable osteofixation devices in craniomaxillofacial surgery. Oral Surg. Oral Med. Oral Pathol. Oral Radiol. Endod. 94, 5, 2002.

46. Ciccone, W.J., II, Motz, C., Bentley, C., and Tasto, J.P. Bioabsorbable implants in orthopaedics: New develop- 
ments and clinical applications. J. Am. Acad. Orthop. Surg. 9, 280, 2001.

47. Wozney, J.M., and Rosen, V. Bone morphogenetic protein and bone morphogenetic protein gene family in bone formation and repair. Clin. Orthop. 346, 26, 1998.

48. Urist, M.R., Sato, K., Brownell, A.G., Malinin, T.I., Lietze, A., Huo, Y.K., Prolo, D.J., Oklund, S., Finerman, G.A., and DeLange, R.J. Human bone morphogenetic protein (hBMP). Proc. Soc. Exp. Biol. Med. 173, 194, 1983.

49. Hogan, B.L. Bone morphogenetic proteins: Multifunctional regulators of vertebrate development. Genes Dev. 10, 1580, 1996.
50. Alden, T.D., Beres, E.J., Laurent, J.S., Engh, J.A., Das, S., London, S.D., Jane, J.A., Jr., Hudson, S.B., and Helm, G.A. The use of bone morphogenetic protein gene therapy in craniofacial bone repair. J. Craniofac. Surg. 11, 24, 2000.

Address reprint requests to: Paul H. Krebsbach, D.D.S., Ph.D. 1011 N. University Ave. Ann Arbor, MI 48109

E-mail:paulk@umich.edu 


\section{This article has been cited by:}

1. Mr. Chang Hun Lee, Dr. Nicholas W. Marion, Dr. Hollister J Scott, Prof. Jeremy Mao . Tissue Formation and Vascularization of Anatomically Shaped Human Tibial Condyle in VivoTissue Formation and Vascularization of Anatomically Shaped Human Tibial Condyle in Vivo. Tissue Engineering Part A 0:ja. . [Abstract] [PDF] [PDF Plus]

2. Peter J. Yang , Johnna S. Temenoff . 2009. Engineering Orthopedic Tissue InterfacesEngineering Orthopedic Tissue Interfaces. Tissue Engineering Part B: Reviews 15:2, 127-141. [Abstract] [Full Text] [PDF] [PDF Plus]

3. Michael Keeney, Abhay Pandit . 2009. The Osteochondral Junction and Its Repair via Bi-Phasic Tissue Engineering ScaffoldsThe Osteochondral Junction and Its Repair via Bi-Phasic Tissue Engineering Scaffolds. Tissue Engineering Part B: Reviews 15:1, 55-73. [Abstract] [Full Text] [PDF] [PDF Plus]

4. Ji-Hyun Ahn, Tae-Hyeong Lee , Jong-Soo Oh, Su-Yeon Kim, Hyun-Jung Kim , Il-Kyu Park, Baek-Sun Choi , Gun-Ii Im . A Novel Hyaluronate-Atelocollagen/ $\beta$-TCP-Hydroxyapatite Biphasic Scaffold for the Repair of Osteochondral Defects in RabbitsA Novel Hyaluronate-Atelocollagen/ $\beta$-TCP-Hydroxyapatite Biphasic Scaffold for the Repair of Osteochondral Defects in Rabbits. Tissue Engineering Part A, ahead of print. [Abstract] [PDF] [PDF Plus]

5. Jian Li , Shobha Mareddy, Dawn Meifang Tan, Ross Crawford, Xing Long, Xigeng Miao , Yin Xiao . A Minimal Common Osteochondrocytic Differentiation Medium for the Osteogenic and Chondrogenic Differentiation of Bone Marrow Stromal Cells in the Construction of Osteochondral GraftA Minimal Common Osteochondrocytic Differentiation Medium for the Osteogenic and Chondrogenic Differentiation of Bone Marrow Stromal Cells in the Construction of Osteochondral Graft. Tissue Engineering Part $A$, ahead of print. [Abstract] [PDF] [PDF Plus]

6. Timothy M. O'Shea , Xigeng Miao . 2008. Bilayered Scaffolds for Osteochondral Tissue EngineeringBilayered Scaffolds for Osteochondral Tissue Engineering. Tissue Engineering Part B: Reviews 14:4, 447-464. [Abstract] [PDF] [PDF Plus]

7. Sota Kitahara, Koichi Nakagawa , Robert L. Sah , Yuichi Wada , Tetsuro Ogawa , Hideshige Moriya , Koichi Masuda . 2008. In Vivo Maturation of Scaffold-free Engineered Articular Cartilage on HydroxyapatiteIn Vivo Maturation of Scaffold-free Engineered Articular Cartilage on Hydroxyapatite. Tissue Engineering Part A 14:11, 1905-1913. [Abstract] [PDF] [PDF Plus]

8. Yohei Ito, Nobuo Adachi, Atsuo Nakamae, Shinobu Yanada, Mitsuo Ochi. 2007. Transplantation of Tissue-Engineered Osteochondral Plug Using Cultured Chondrocytes and Interconnected Porous Calcium Hydroxyapatite Ceramic Cylindrical Plugs to Treat Osteochondral Defects in a Rabbit Model. Artificial Organs, ahead of print070802063815010-???. [CrossRef]

9. Limin Wang, Michael S. Detamore . 2007. Tissue Engineering the Mandibular CondyleTissue Engineering the Mandibular Condyle. Tissue Engineering 13:8, 1955-1971. [Abstract] [PDF] [PDF Plus]

10. Limin Wang, Michael S. Detamore. 2007. Tissue Engineering the Mandibular Condyle. Tissue Engineering, ahead of print070124172705001. [CrossRef]

11. Antonios G. Mikos, Susan W. Herring, Pannee Ochareon , Jennifer Elisseeff, Helen H. Lu, Rita Kandel, Frederick J. Schoen , Mehmet Toner, David Mooney, Anthony Atala , Mark E. Van Dyke, David Kaplan , Gordana Vunjak-Novakovic . 2006. Engineering Complex TissuesEngineering Complex Tissues. Tissue Engineering 12:12, 3307-3339. [Abstract] [PDF] [PDF Plus]

12. Wei Sun, Yongnian Yan, Feng Lin, Myron Spector. 2006. Biomanufacturing: A US-China National Science Foundation-Sponsored Workshop. Tissue Engineering, ahead of print060518071048001. [CrossRef]

13. Wei Sun, Yongnian Yan , Feng Lin , Myron Spector . 2006. Biomanufacturing: A US-China National Science Foundation-Sponsored WorkshopBiomanufacturing: A US-China National Science Foundation-Sponsored Workshop. Tissue Engineering 12:5, 1169-1181. [Abstract] [PDF] [PDF Plus]

14. Chia-Ying Lin, Rachel M. Schek, Amit S. Mistry, Xinfeng Shi , Antonios G. Mikos, Paul H. Krebsbach , Scott J. Hollister . 2005. Functional Bone Engineering Using ex Vivo Gene Therapy and Topology-Optimized, Biodegradable Polymer Composite ScaffoldsFunctional Bone Engineering Using ex Vivo Gene Therapy and Topology-Optimized, Biodegradable Polymer Composite Scaffolds. Tissue Engineering 11:9-10, 1589-1598. [Abstract] [PDF] [PDF Plus] 